\title{
Análise e memória \\ (recordações de Enzo Faletto)
}

Fernando Henrique Cardoso

H á quarenta anos, em 1967, Enzo Faletto e eu terminávamos, em Santiago do Chile, o manuscrito de um livro, D ependência edesenvolvimento na Amé rica Latina. $N$ ele fazíamos um diálogo com as principais interpretações sobre 0 tema do desenvolvimento. $\mathrm{A}$ instituição das $\mathrm{N}$ ações Unidas onde trabalhávamos, a Comissão E conômica da América Latina- C epal, propunha uma abordagem para os estudos sobre o desenvolvimento econômico conhecida como estruturalismo latino-americano. 0 principal formulador dessa teoria foi o economista argentino Raúl Prebisch, mas ela teve vários desdobramentos.

Prebisch caracterizou o subdesenvolvimento da região como sendo estrutural. Baseando-se nas análises estatísticas de $\mathrm{H}$ ans Singer, importante economista da $\mathrm{ONU}$, assinalou que havia uma perda continuada no comércio internacional que limitava as possi bilidades de crescimento dos países subdesenvolvidos. Isso porque as trocas internacionais se limitavam à importação de produtos manufaturados eas exportações se compunham de matérias-primas e produtos agrários, as chamadas commodities. 0 ra, as commodi ties continham baixo conteúdo tecnológico e os salários pagos aos trabalhadores que as produziam eram reduzidos. Por outro lado, apesar do alto componente tecnológico da produção de manufaturas, que deveria barateá-las, os sindicatos e demais setores organizados das sociedades de senvolvidas apropriavam-se dos ganhos de produtividade. Esses eram os 
fundamentos sociai s e políticos para a existência de uma diferença crescente entre os países do centro e os da periferia: ela era estrutural e não se explicaria por motivos conjunturais ligados apenas à evolução dos preços.

M esmo considerando-se a absorção de novas tecnologias pelos setores exportadores, elas não se difundiam para o conjunto da economia, nem mesmo para todo o setor agrícola. Criava-se, dessa forma, uma diferença básica com os países centrais. $N$ estes, os ganhos de produtividade de um setor espalhavam-se rapidamente por toda a economia. Embora as economias desenvolvidas fossem diversificadas, tornavam-sehomogêneas do ponto de vista da absorção do progresso tecnológico. Já nos países periféricos, os eventuais ganhos de produtividade concentravam-se nas áreas exportadoras, formando-se economias especial izadas e heterogêneas. Essa situação diferencial constituiu-se a partir da expansão do capitalismo comercial, que ligou os países subdesenvolvidos da periferia, por meio do mercado internacional, aos países de desenvolvimento originário, que se encontravam em estágio econômico e tecnológico mais avançado.

M enciono a tese para mostrar, primeiro, que o raciocínio econômico da Cepal nada tinha do simplismo da versão vulgar da teoria do imperialismo, sempre pronta a ver uma mera imposição política dos países centrais aos países da periferia. Segundo, que o estrutural ismo latino-americano sempre tratou de combinar análise econômica com análise política.

Prebisch nunca esqueceu que o processo de desenvolvimento tem um componente indispensável de ganhos de produtividade, os quais são impossíveis sem desenvolvimento científico e tecnológico e sem acumulação de capitais. M as tampouco esqueceu de mostrar por que a teoria econômica clássica não estava funcionando: de um lado, porque nos países industrializados os sindicatos lutavam por maiores fatias do produto nacional e, da mesma forma, o Estado queria mais impostos para construir uma sociedade melhor; de outro lado, porque a concentração agroexportadora deformava a estrutura das economias periféricas.

Q ue fazer para reverter essa situação? A resposta era complexa. Seria preciso, a partir do Estado, fazer o que o mercado não fez: forçar a acumulação de capitais por meio dos impostos e ampliar o componente tecnológico da produção. 0 u seja, industrializar os países, liberando-os da camisade-força da produção agrário-pastoril e mineradora. Em vez de orientar a produção para o mercado externo, orientá-la primordialmente para o mercado interno. Como a deterioração constante dos termos de intercâmbio levava a crises cíclicas da balança de pagamentos, havia que controlar 0 
câmbio. Para estimular a reorientação da economia hacia adentro, algum planejamento seria conveniente, bem como era necessário atrair capitais, nacionais e estrangeiros, e dinamizar o crescimento econômico. Tudo isso implicava melhorar a eficiência do manejo da máquina e das políticas públicas.

No livro queescrevi com Faletto, desdobramos o raciocínio estruturalista. Incluímos outros aspectoshistóricose políticos que condicionaram o de senvolvimento das economias periféricas. Em vez de ver essas economias de modo homogêneo, mostramos queem cada uma delas os grupos sociais eas classes articulavam-se de modo variável, entre si e com os países centrais. H ouve dois tipos básicos de inserção das economias da América Latina no sistema internacional: um, quando a produção exportadora se manteve sob controle de produtores nacionais. O utro, quando houve inversão estrangeira. $\mathrm{H}$ istoricamente essa diferenciação dependeu de muitos fatores, como a abundância de terras ou de recursos minerais. $D$ ependeu também, desde 0 período colonial, deexistir ou não uma população numerosa, da capacidade dos grupos e das classes locais de se estruturar em sistemas de poder eficientes, de negociar com os setores externos, e assim por diante. Em qualquer caso, não havia a inevitabilidadedeuma forma espećfica dedependência, pois esta não decorreu demera imposição externa, mas da combinação defatores externos e internos e das alianças entre eles.

Em certos casosformaram-seeconomias deenclave, como as chamamos, pois havia inversões estrangei ras diretas no setor exportador. Raramente algum setor nacional participou desse tipo de exploração. Em geral, os agricultores emineradores nacionais desempenharam um papel secundário nos enclaves durante o século XIX. As classes médias beneficiavam-se do sistema apenas marginalmente, utilizando o Estado local como coletor eredistribuidor dos impostos cobrados aos enclaves. 0 s trabalhadores desse setor, sim, dependiam diretamente dele, en quanto a massa agrícola do setor tradicional ficou marginalizada, sobretudo nos países com vastas populações indígenas (como a Bolívia, a América Central e, em menor escala, o C hilee o M éxico, por exemplo). Em outros casos, as classes proprietárias locais dedicavam-seà agricultura, fazen do elas próprias a acumulação decapitais (dada a abundância de terras e a mão-de-obra barata, quando não escrava) e podendo, mais tarde, diversificá-los para a produção industrial (caso, por exemplo, da Argentina e do Brasil).

A ênfase do livro não foi, portanto, na dependência, embora elehouvesse sido lido com esse viés porque a "teoria da dependência" estava na moda 
(apesar de nos havermos oposto explicitamente a essa versão simplificada da teoria do imperialismo). Enfatizamos, isso sim, a variabilidade das formas de integração ao mercado mundial eas alternativas que existiam para o crescimento econômico dos países, mesmo em situações de dependência.

N o século XX, em meados dos anos 1960, já se notava certa tendência para a associação entre capitais nacionais e estrangei ros na produção local, sobretudo no setor industrial enos serviços (estes, como osfinanceiros ou os detransporte, tinham forte participação estrangeira, sobretudo inglesa, desde o século XIX). D epois da Segunda G uerra M undial, aproveitando-se do boom quea guerra provocara na produção de manufaturas, o capital estrangeiro tornou-se ativo nos investimentos industriais, notadamente no Brasil e, em menor proporção, no M éxico. Em outras palavras, o que chamamos de "a nova forma de dependência" era, na verdade, o início do processo que veio a completar-se mais tarde e a ser conhecido como gl obalização.

$N$ aquela época, nem sequer a noção de empresas multinacionais era de uso corrente. Eram chamadas detrustes, poisa expressão "empresa multinacional" só foi cunhada por Raymond Vernon em 1971. Q uedizer, então, da globalização? N ada sabíamos na época. N ão obstante, era dos primórdios dela quetratávamos, usando outra expressão (internacionalização do mercado). M ostramos, inclusive, que, na medida em que o capital externo investia para produzir bens industriais não exportáveis, necessitava da expansão do mercado interno, com todas as conseqüências políticas que isso acarretava. Chegamos a prever que a continuidade do desenvolvimento na periferia se tornara possível, contrariando a crença difundida na época de que isso seria impossível no regime capitalista. Para manter a expansão futura da produção, dissemos, haveria que exportar de maneira distinta das economias primário-exportadoras, pois haveria que ganhar o mercado internacional para produtos manufaturados. 0 mercado externo tornar-se-ia condição para a continuidade do crescimento econômico, dando a volta, assim, ao argumento inicial quesustentava que o motor do desenvolvimento deveria ser 0 mercado interno. $N$ ão tínhamos noção entretanto - nem poderíamos ter dos impactos enormes que a nova fase do capitalismo, impulsionada pela revolução nas tecnologias de comunicação, acarretaria, sobretudo nos sistemasfinanceiros.

Em nossa "visão", acentuávamos as diferenças entre as estruturas socioeconômicas dos países do centro e as dos países periféricos. A esse enfoque acrescentamosa dimensão histórica, para mostrar como seforam construindo as diversas situações de dependência (entendendo-se por tal umaaborda- 
gem integrada dos fatores econômicos, sociais e políticos na formação do capitalismo na periferia). N osso livro mostrou, principalmente, que havia diferenças entre os paísesquanto às oportunidades de crescimento edeintegração ao mercado internacional. Também diminuiu o peso relativo dos fatores externos nas relações entre as classes locais e delas com as internacionais, eanalisou as modificações que ocorreram nos países da região à medida que variaram as condições gerais do capitalismo.

$M$ antivemos a preocupação com os graus de autonomia nacional e, portanto, com o papel que o Estado jogaria nas decisões de desenvolvimento. $\mathrm{N}$ ão sevislumbrava ainda a relativa autonomia das empresas multinacionais diantedosEstados, mesmo nos países centrais, nem seimaginavauma situação em que as grandes organizações criadas para estabilizar a ordem econômica e oferecer maiores oportunidades de crescimento aos países subdesenvolvidos, como o FM I eo Banco M undial, parecessem frágeis para cumprir a mi ssão. H ojesemostram insuficientes para controlar o dinamismo daeconomia global e das empresas multinacionais, e equilibrar o crescimento das economias emergentes.

N o capítulo final de D ependência e desenvolvimento, que descrevea nova dependência, salientamos que alguns países, como a C hina e a U nião Soviética, tomaram decisões políticas que lhes permitiram maior autonomia no mercado internacional e no desenvolvimento econômico. 0 preço pago para esse resultado foi o fechamento inicial da economia, o Estado onipresente, a supressão das liberdades e a concentração de recursos humanos e técnicos na busca de objetivos estratégicos de crescimento econômico e poder militar. Tal percurso parecia excluído do horizonte do mundo ocidental e mesmo da maioria dos países da América Latina, que al guns chamam de Extremo $\mathrm{O}$ cidente. Com a exceção de Cuba e de umas poucas e fracassadas tentativas de assegurar a autonomia pelo isolamento, a maioria dos países da região fez outro percurso. Ainda assim, não se pode entender a conjuntura política nem as posições e análises intelectuais daquela época sem ter presente que União Soviética, Cuba e C hina constituíam um contraponto ao estilo de desenvolvimento do capitalismo ocidental.

D epois da queda do muro de Berlin, o que simbolizou o fim da bipolaridade entre União Soviética e Estados Unidos (ou o "mundo livre", como pretensiosamente se qualificava o bloco ocidental), e depois dos avanços tecnológicos, com o predomínio da high tech e da revolução dos meios de comunicação e de transporte, o mundo é outro. $\mathrm{N}$ em melhor, nem pior, mas diferente. As constantes modificações tecnológicas, que al- 
teram o modo de produção e sobretudo a escalada do capital financeiro que se globalizou (graças, entre outros motivos, à internet), redesenharam a ordem mundial.

$N$ ão creio que Enzo se sentisse à vontade e conformado com essa nova ordem econômico-política chamada gl obalização. C omo intelectual, trataria de analisá-la sem paixão e de vislumbrar os caminhos possíveis para a América Latina, bem ou mal, ajustar-se às circunstâncias. Como pessoa, continuaria caminhando por seu aprazível bairro santiaguino de Ñ uñoa, recordando a saga dos anarquistas espanhóis na luta contra Franco e sonhando com uma ordem maisigualitária e menos absorvida pelas forças do mercado.

A Enzo eu devo muito do quepudever edeixar registrado da história tão variada e, ao mesmo tempo, com tanto em comum de "nuestra América". Ele sabia disfarçar sua erudição na simplicidade e na graça da palavra. Era um professor admirável. Rigoroso na análise, escrevia dando a impressão de que não gostava do ofício de escritor edizia quenão se deveria levar muito a sério o que pensava. D eixou, sem alarde, obra notável, como historiador das idéias, como sutil analista das tendências do mundo contemporâneo.

$\mathrm{N}$ a nota que enviei a Santiago na ocasião do falecimento de Enzo, quis expressar as saudades do amigo. Poucas pessoas terão cruzado por mim com sua elegância de alma, com o sentimento encabulado de uma fraternidade calorosa que se escondia na ironia, com a gentileza de um príncipe, na mais pura acepção da palavra. Recordo-me tão bem da primeira vez que estive com ele. Fui ao C hileencontrar-me com dom JoséM edina Echavarría, para quem eu escrevera um trabalho sobre os empresários brasileiros. À noite, em uma das raras noites quentes de verão, quando se sente nas ruas o perfumedas árvores, fui ter à casa deEnzo, acompanhado por Francisco W effort. Lá se bebia vinho e se escutava tangos. Parodiando N eruda: podiam escutar-se os tangos mais tristes aquela noite. D aquela noite em diante tornamonos amigos.

D epois, cada vez queeu visitavaSantiago, como senador, ministro ou presidente, Enzo vinha à embaixada. M antínhamos o diálogo sem nenhuma confusão entre a relação de amizade e os compromissos institucionais. No tom freqüentemente cético de suas observações Enzo tinha uma nostal gia imensa da época em queseimaginava ser possível juntar a vontaderevolucionária com a sensibilidade romântica sem levar muito a sério as instituições.

N ão foi só meu amigo. Foi de toda a família. Ruth, Paulo, Luciana, Beatriz, todos o amavam, e isso desde quando meus filhos eram crianças. 
Porque Enzo Faletto, por grandes que tenham sido suas marcas na vida intelectual e profissional, foi sobretudo uma grande pessoa que continua presente em nossas memórias de cada dia.

\section{Resumo}

Análise e memória (recordações de Enzo Faletto)

Revendo a tese defendida em D ependência e desenvolvimento na América Latina, escrito em colaboração com Enzo Faletto, o autor mostra como o raciocínio econômico da Cepal nada tinha do simplismo da versão vulgar da teoria do imperialismo, e que o estruturalismo latino-americano, ao combinar sempre análise econômica com análise política, revelou que em nenhum país da região havia a inevitabilidade de uma forma específica de dependência, mas a variabilidade das formas de integração ao mercado mundial e, portanto, das alternativas para o seu crescimento econômico. Isso, com a exceção de Cuba, isolada na sua ligação com o bloco soviético. No mundo de hoje, transformado pela globalização, essa nova forma de relação capitalista, não se pode entender a conjuntura política nem as posições e análises intelectuais daquela época sem ter presente que União Soviética, Cuba e China constituíam um contraponto ao estilo de desenvolvimento do capitalismo ocidental.

Palavras-chave: América Latina; Teoria da dependência; Estruturalismo latino-americano; Globalização.

\section{Abstract}

Analysis and memory (recollections of Enzo Faletto)

Returning to the thesis defended in D ependency and D evelopment in Latin America, written in collaboration with Enzo Faletto, the author shows how the economic reasoning of Cepal (Economic Commission for Latin America) had nothing of the simplifying nature of the vulgar version of the theory of imperialism, and that Latin American structuralism, by combining economic analysis with political analysis, re vealed that no country in the region was inevitably condemned to a specific form of dependency. Instead, there was considerable variability in the forms of integration to the world market and, therefore, in the alternatives for their economic growth, apart from Cuba, isolated in its link to the Soviet block. In today's world, transformed by globalization, this new form of capitalist relationship, we cannot understand either the political setting or the intellectual positions and analyses of the earlier period without recalling that the Soviet Union, Cuba and China formed a counterpoint to western capitalism's style of development.

Keywords: Latin America; Theory of dependency; Latin American structuralism; G lobalization.
Texto recebido em 2/ 5/2007 eaprovado em 2/5/2007.

Fernando Henrique Cardoso é professor emérito da U SP e presidente do iFH C. Email: comunicacao@i fhc.org.br. 